\title{
Enkele etiese aspekte van natuurbewaring
}

\author{
B J Engelbrecht
}

Universiteit van Pretoria

\begin{abstract}
Certain ethical aspects of nature conservation

The present worldwide ecocrisis is of such a magnitude and seriousness that man's life, living standards, fut'ire and very existence on earth are at stake. The main components of this man-made ecocrisis are the existing increasing overpopulation of earth, the exorbitant demands on the natural resources of our planet, the pace at which the non-renewable energy and other resources are being depleted and the pollution of the whole earth. In this paper we shall treat the population explosion problem as perhaps the most basic of the four components of the ecocrișis; we shall also give special attention to the associated ethical issues.
\end{abstract}

\section{INLEIDING}

Die bewaring van 'n bepaalde entiteit of entiteite kan alleen sinvol verstaan en uitgevoer word, indien dit gesien word binne die omgewing, die ekosisteem waarin dit voorkom en waarin dit dikwels in die loop van eeue aangepas is.

'Ekologie' is 'n woord wat tradisioneel in die biologiese wetenskappe gebruik is. 'Ekologie' beteken daar dié wetenskap wat die verhouding bestudeer tussen lewende organismes (soos plante, diere, insekte, visse) met hulle omgewing en die daaruit voortvloeiende lewenspatrone. Veranderings in die ekosisteem bring aanpassing en

- Hierdic artikel is 'n verwerking van my lesing voor dic (iroen Kongres van die R(iN mel dic tema 'Dic mens, dic kunsie en sy omgewing', Maart 1990, Pretoria. Ek dra dit op aan my vriend en kollega vir 31 jaar aan dic Universitcit van Pretoria - prof dr A D Pont met sy aftrede. 
dikwels drastiese veranderings in die leefwyse van die lewende organismes in daardie omgewing mee.

Vanaf die industriële revolusie en veral in die afgelope paar dekades het die mens die ekosisteme oor feitlik die hele wèreld s 6 verander dat hy nie meer net toeskouer en verbruiker in hierdie veranderingsproses is nie, maar dat hy dié een geword het wat die ekosisteem aktief drasties verander en veral as dié een wie se lewe, lewenskwaliteit en voortbestaan self op die spel is. En waar die mens, hierdie keer as bedreigde wat sy toekoms betref, ten nouste betrokke is, daar tree etiese vrae na vore wat dringend om beantwoording vra. Die etiek is onlosmaaklik aan die mens as denkende, willende en voelende wese verbonde. Etiek kyk na die bestaande toestand, na dit wat is, en vanuit bepaalde norme (waarvan hy glo dat hulle universeel is) wys hy op wat behoort te wees. Etiek sê dus in verband met ons gesindhede en handelinge of hulle goed of sleg, reg of verkeerd, geoorloof of nie geoorloof is.

\section{DIE VIER KOMPONENTE VAN DIE EKOKRISIS}

Hier is die 'is' ter sake, dit wil sê die wèreldwye ekokrisis wat die inwoners van SuidAfrika ten nouste raak. Die huidige ekokrisis het vier konstituiitiewe komponente wat ten nouste onderling saamhang en mekaar wedersyds beïnvloed. Wat van uiterste belang is, is dat dit nie sal help om net een of twee komponente te probeer oplos nie. Die matematiese Forrester-Meadows Wêreldmodel en die werk van Die Klub van Rome het, nieteenstaande kritiek, onteenseglik aangetoon dat indien die mens nie let op 'the limits of growth' en 'the dynamics of growth in a finite world' en streef na 'n 'global equilibrium' wat al vier komponente van die ekokrisis tegelykertyd aanspreek nie, daar nog in die lewe van die volgende geslag ' $n$ massale ineenstorting van die wêreld en bygevolg van die mens se lewenspatroon en lewensstandaard sal plaasvind.

\section{Die bevolkingsontploffing}

Die eerste en myns insiens vernaamste komponent in die huidige wêreldwye ekokrisis, is die geweldige bevolkingsgroeitempo. Hier word slegs 'n paar goed-gekontroleerde syfers noem:

Die wêreldbevolking staan tans op ongeveer 5300 miljoen. In 1988 het die bevolking met 88 miljoen vermeerder, in 1990 met 91 miljoen en tot die jaar 2000 met 97 miljoen gemiddeld per jaar, dit wil sé gemiddeld word elke drie sekondes 'n baba gebore. Hierdie byna 1000 miljoen bykomende mensies sal voor en vanaf die jaar 2000 voedsel, kleding, huisvesting, mediese sorg, energie vir vervoer en tuis- 
gebruik ensovoorts nodig hê, terwyl seker 600 miljoen ekstra werkgeleenthede geskep sal moet word en 'n effens groter getal opvoedingsfasiliteite nodig sal wees.

Die totale Afrika-bevolking is tans ongeveer 620 miljoen; in die jaar $2000 \mathrm{sal}$ hulle 878 miljoen tel, dit wil sê weer eens 158 miljoen mensies meer om te voed, te klee ensovoorts. Die Afrika-bevolking verdubbel tans elke 24 jaar.

Suider-Afrika se beraamde bevolking staan tans op 38 miljoen en sal in 1992 40 miljoen tel, 50 miljoen in die jaar 2000 en 60 miljoen agt jaar later. Dié geweldige groeitempo geskied veral onder die swart mense van Suid-Afrika wat elke 25 jaar verdubbel as gevolg van ' $n$ heel ander filosofie in verband met kinderverwekking as by die westerlinge, terwyl die noodsaaklike feit van toekomsbeplanning by hulle feitlik heeltemal ontbreek.

Ten opsigte van swart onderwys beteken dit ' $n$ toename van matrikulante vanaf 40000 in 1983 tot 186000 in 2000 . Dit beteken dat jaarliks 450 nuwe skole gebou en 17000 nuwe onderwysers opgelei moet word.

Ten opsigte van ander fasette beteken dit die jaarlikse skepping van ongeveer 300000 werksgeleenthede, die bou van 130000 nuwe huise en die daarstelling van 1800 nuwe hospitaalbeddens met die gepaardgaande infrastruktuur daarvoor.

Wat die blankes in Suid-Afrika betref, is die totale fertiliteitskoers 1,9 kinders per vrou teenoor die 2,1 kind per vrou wat die vervangingsvlak uitmaak. Dit was in 1990. Volgens die Jaarverslag van die Departement Nasionale Gesondheid van 13 Mei 1991, het dit alreeds afgeneem na 1,7 kinders per blanke vrou.

\section{Welvaartseise}

Die tweede komponent van die genoemde ekokrisis, kan 'welvaartseise' of 'beskawingsdruk' genoem word. Kortweg beteken dit die mense se volgehoue eise vir 'n hoër welvaartspeil en veral die druk van die Derde Wêreld, wat vroeër met min tevrede was, om op 'n gelyke basis aan alle 'vrugte' van die aarde en van die tegnologie deel te hê, dikwels sonder enige teenprestasie, bloot omdat hulle mense is. Dit is duidelik dat hierdie eise en druk spruit uit die bevolkingsgroeitempo van die verlede tot op vandag, gepaard met die visie dat 'die rykes' vir die eisers se agterstand en ellende verantwoordelik is en dat hulle en die Staat die agterstand onmiddellik moet uitwis. Van eie skuld en verantwoordelikheid is daar geen sprake nie.

\section{Uitputting van onhernubare hulpbronne}

Genoemde twee komponente van die krisis sou natuurlik niks ten opsigte van die ekosisteem van die aarde as die mens se leefwêreld gewees het, indien die mens oor 
onbeperkte natuurlike hulpbronne beskik het nie. Wat energie as integrale deel van die mense se welvaart, menswaardige leefwyse en selfs voortbestaan betref, word onderskei tussen die onuitputlike energiebronne soos son-energie, wind-energie, die see se golfenergie, plant-energie (soos bome) ensovoorts. Dan is daar die uitputbare of onhernubare energiebronne, veral die fosielbrandstowwe soos olie, steenkool en aardgas. Navorsers het 'n dekade of wat gelede tot die ontstellende ontdekking gekom dat die mens die afgelope eeu besig is om hierdie uitputbare energiebronne teen 'n rasende tempo op te verbruik. Die vraag is: Wat gaan die mens se agterkleinkinders sonder dié energie maak wat hy met die druk van 'n knoppie as vanselfsprekend aanvaar? Een gevolg sal natuurlik wees die ineenstorting van die vervoervervaardigingsbedryf (motors, treine en vliegtuie) met die gepaardgaande massale werkloosheid van miljoene der miljoene werkers wêreldwyd.

Kernenergie lyk na 'n oplossing. Dit is egter 'n hoogs riskante bedryf en uiteindelik ook uitputbaar.

In hierdie verband word slegs 'n paar interessante sake genoem, hierdie keer nie uit Afrika-Asië nie, maar uit die VSA.

Elke individu van die VSA gebruik gemiddeld 5,3 maal soveel energie as enige ander mens in die res van die wêreld. Hulle spreuk is: 'Vryheid en gelykheid van alle mense, maar [en hier lê die vangplek] net solank as ek 5,3 maal soveel as julle mag besit en verbruik!'

Samehangend hiermee het Marvin Harris 'n wiskundige formule ontwerp om uit te druk wat die verhouding tussen die kalorieë-inset om voedsel te produseer is, en die kalorie-waarde van die voedsel wat geproduseer word. In sommige Afrikagemeenskappe is dit éen kalorie-inset teenoor 9,6 uitset. By andere, 1 inset teen 6 uitset. In die VSA is dit egter 22000 kalorieë-inset om 270 kalorieë voedsel (beesvleis en vet) te produseer, dit wil sê 81,50 inset teenoor ' $n$ uitset van 1 !

Dit is ook vasgestel dat toe Amerika landbougrond intensief met die oog op gewasverbouing begin bewerk het, daar gemiddeld vyftien sentimeter vrugbare landbougrond was, wat deur millennia ontstaan het, maar dat daar deur erosie en someer vandag net gemiddeld vyf sentimeter daarvan oor is! Volgens dr Norman Myers sal dit meer as 1000 jaar neem om dit te herstel.

\section{Die besoedelingsbedreiging}

Die vierde en laaste komponent van genoemde ekokrisis is die verwoestende besoedeling van die Lebensraum deur die industrië, voertuie en huishoudings met die altyd-teenwoordige bedreiging van kernbesoedeling. Dit is miskien die sigbaarste, maar myns insiens ook die voorkombaarste van die genoemde vier krisis-komponen- 
te, maar daarom nie minder enstig nie. Dit kos Johannesburg byvoorbeeld R20 miljoen per jaar om rommel wat op straat gegooi word, op te ruim en te verwyder.

Die eerste komponent in die besoedelingskrisis is dié van omgewingsbesoedeling - die afvalskrisis. Onderlinge kompetisie en eise deur die moderne samelewing het oorverpakking van verbruikersgoedere in bioonafbreekbare materiale soos polivinielchloried (hierna PVC) (7\%), glas en metaal (elk 11\%) ensovoorts meegebring. Papier bly egter nog die grootste omgewingsbesoedelingsmateriaal naamlik 38 persent. Gesondmakende trefwoorde moet hier wees: Bio-afbreekbaarheid (bv poliëtileen in plaas van PVC-filmmateriaal), bronvermindering, herbenutting en verbrandbaarheid sonder lugbesoedeling.

Die tweede komponent van die besoedelingskrisis is lugbesoedeling wat hoofsaaklik te weeg gebring word deur die verbranding van genoemde fosiel-brandstowwe asook veld- en bosbrande. In sommige wêreldstede asem nie-rokers 'n gelyke hoeveelheid skadelike stof in as iemand wat in 'n suiwer atmosfeer veertig sigarette per dag rook. Verder gee hierdie verbranding gewoonlik gasse af wat suurreën veroorsaak met katastrofiese gevolge vir plantegroei en die daarmee samehangende omgewing.

Die verwarming van die aarde se atmosfeer sal meebring dat die seevlak sal styg, die weer onstabiel sal wees, die kusstreke sal verspoel en die landbou en plantegroei deur dit alles drasties ontwrig sal word.

Die gesondheidsgevaar van die vernietiging van die osoonlaag deur die drukstof in spuitkannetjies is bekend. Hierdie beskadiging sal, indien die gebruik van alle osoonvyandige stowwe onmiddellik gestaak word, slegs binne 'n eeu herstel kan word.

Die laaste komponent in die besoedelingskrisis is waterbesoedeling. Myns insiens is die hardnekkigste besoedelingselement in waterbesoedeling die chemiese besoedeling wat selfs gesuiwerde water só oorverryk met nitrate en fosfate, dat dit 'n geweldige algbloei tot gevolg het, asook ander plae soos waterhiasinte en cormatige watergrasgroei.

\section{ETTESE PERSPEKTIEWE}

Die vraag oor die wyse 'n mens hierdie legio probleme vanuit die etiek benader en beoordeel kom aan die orde. Die oorkoepelende stelling kan gemaak word dat, eties en ook bybels gesien, die mens wel 'n eksentrieke posisie teenoor die res van die natuur het. Genesis 1:26 stel dat die mens God se verteenwoordiger is wat op en oor die aarde sal heers. Psalm 8:7 stel: ' $U$ laat hom heers oor die werk van $u$ hande; $U$ het alles aan hom onderwerp: skape en beeste, alles.' Maar die keerkant 
van die munt van die mens se status en bestaan op aarde is dat sy lewe en lot onlosmaaklik met die natuur verbonde is. In Bybelse beeldspraak word dié saak soos volg uitgedruk: Hy is uit die stof van die aarde gevorm (Gen 2:7), hy is stof en sal weer stof word, hy is aarde en sal daarheen terugkeer, want daaruit is hy geneem (Gen 3:19). Verder het hy ook ten opsigte van sy leefwerreld 'n taak en verantwoordelikheid. Die Bybel sê dit so: Hy moet die aarde bewoon en bewerk (Gen 1:28). Genesis 2:15 sê verder dat as verteenwoordiger van God op aarde, hy die tuin moet bewerk én oppas. Die basiese fout van die mens se instelling wat vanaf die industriële revolusie sigbaar begin word, is dat hy sy eksentrisiteit en heerskap ten opsigte van die natuur egoïsties ontplooi het en sodoende uitbuiter en selfs vernietiger van die natuur geword het. Sy onlosmaaklike lotsgebondenheid met die natuur en sy oppasverantwoordelikheid en -taak ten opsigte daarvan het hy totaal opsy geskuif en vergeet. Wat vandag nodig is, is 'n antropologie, 'n mensbeskouing wat die verband en fyn balans tussen kultuur en natuur sal herstel. Hierdie nuwe mensbeskouing kan alleen deur ' $n$ intensiewe proses van heropvoeding geskied.

Bostaande stelling is nie nuut nie. John Muir, wat in die VSA 'the first ecologist' genoem word, het alreeds in $\mathbf{1 8 6 9}$ die volgende in dié verband opgemerk: 'Everything is hitched to everything else. If man doesn't act as an integral part of a harmonious whole, he'll bring inbalance and beget ultimate loss and poverty.' Hierdie grondstelling word tans deur myself (Engelbrecht 1988), deur Buitendag (1985) en Schoeman (1990) raakgesien en uitgewerk. Laasgenoemde sề onder andere (Schoeman 1990:267): " $n$ Holistiese wêreldbeeld moet dringend in 'n aanneembare vorm vir vandag se mens ontwerp en aanvaar word, "before we destroy ourselves and our envirnoment".'

Ten opsigte van die bevolkingsgroeitempo is die etiese vraag of die owerheid in die sfeer van die uiters-persoonlike vryheid van individue mag en kan ingryp om beperkende maatreëls onder die gekleurde bevolking van Suid-Afrika en dan veral ten opsigte van die swart mense af te dwing ter wille van hulle eie en almal se oorlewing. Hoe sal hulle filosofie van baie kinders as rykdom, sekuriteit en politieke mag, verander kan word asook hulle siening dat hulle toestand 'die ander se skuld' is en wat die toekoms betref, moet 'die ander', veral die Staat, verantwoordelikheid aanvaar en nie hulle nie?

Dit is waar dat welvaart die groeikoers by hulle effens verlaag, maar om daarop staat te maak, is te min en te laat. Bowendien is daar nog, behalwe in Suid-Afrika, die miljoene van die Derde Wêreld oor wie die regering in Suider-Afrika geen seggenskap het nie!

Wat die hoë peil van welvaart betref en die eis dat alle mense gelyke deelname aan al 'die vrugte van ons aarde' moet hè, is die etiese vraag weer eens of die ower- 
heid ooit die individu of gesin se vryheid in verband met die besteding van sy/haar inkomste sal kan beperk en beheer.

Teoreties is die oplossing eenvoudig: Verlaag die welvaartspeil baie drasties. Die praktiese probleem is: Deur wie? Wie wil en kan dit wêreldwyd doen en teen watter prys?

Dit is duidelik dat die rasende tempo van die opverbruik van die uitputbare energiebronne en die besoedelingsprobleem onlosmaaklik met die absolute wenslikheid van die verlaging in die bevolkingsgroeikoers en welvaartspeil saamhang. Trouens, aan die wortel van die hele ekokrisis lê één basiese faktor wat met vyf woorde omskryf kan word: Getalle, getalle en nogmaals getalle. Koppel daaraan die onrealistiese welvaartseise van beide die een biljoen 'super-armes' én die een biljoen 'super-rykes' (Myers 1991), dan is die toekoms van al 5,3 biljoen mense en alle lewe op hierdie planeet maar duister.

Genoemde dr Norman Myers, ontvanger van die Wêreldfonds vir Natuur se goue medalje, meen dat die kern van die wêreldwye bevolkingsprobleem daarin geleë is dat daar 1 biljoen super-verarmdes van die wêreld se 5,2-5,3 biljoen mense is ên 1 biljoen super-rykes. Die super-verarmdes het eintlik geen alternatief as hulle vernietigende lewenswyse nie, terwyl die super-rykes net so 'n groot las op die omgewing plaas met hulle uitspattige materiële eise.

Verwant aan dié beskouing is die opvatting van Ruffie (The population altemative) en Patzer (The numbers problem, in The great outdoors [vol 86] 1990:36) dat 'n onregverdige sosiale bestel die skuld moet dra vir Suid-Afrika se bevolkingsprobleem en die gevolglike ekokrisis. Hulle slotsom is: 'The only way to stabilise a population is through providing or initiation of social and economic security...In modern society the most important thing...is to create and offer employment so none is excluded from the social order.'

Uit wat hierbo gestel is, spreek hierdie standpunte nie die kern van die wèreldwye ekokrisis aan nie.

Indien ons die kern van die ekokrisis besef, dan word dit ook duidelik dat die bewaringsywer en bewaringspogings in verband met 'n paar bedreigde diere, plante en plekke in werklikheid maar 'n baie klein druppeltjie in die emmer is. Om gedurigdeur hierop te hamer, kan die wye publiek psigologies afgestomp word en kan hulle ore en oë gesluit word vir die dodelike erns van die wêreldwye ekologie-krisis waarin die mens se toekoms op die aarde op die spel is. 


\section{SLOTOPMERKING}

Ten slotte word die volgende beklemtoon:

Geen oplossing sal werk as daar nie 'n oplossing kom vir al vier genoemde komponente van die wêreldwye ekologiese krisis nie.

Teologies gestel: Hierdie aarde is God se aarde en behoort aan Hom. Ons, as sy verteenwoordigers, mag hierdie feit nooit vergeet nie - nie in ons gesindheid nie, nie in ons denke, nie in ons beplanning en ook nie in ons dade nie.

\section{INLIGTING EN LTERATUUR OOR EKOLOGIE}

\section{Belangrike persone en instansies}

* Noel Brown is direkteur van die New Yorkse kantoor van die VV se omgewingsprogram.

- Gro Harlem Brundtland is die Noorweegse Eerste Minister en was referent by die Kanadese Kongres oor lugbesoedeling.

- IEA is die Weste se Internasionale Energie-Agenskap.

- Dr Boet Schoeman is die adjunk Direkteur-generaal van Bevolkingsontwikkeling en was referent by die onlangse RGN-seminaar oor Bevolkingsneigings.

- Dr Rina Venter is die Minister van Nasionale Gesondheid en Bevolkingsontwikkeling en het by die onlangse byeenkoms van die Raad vir Bevolkingsontwikkeling in Durban opgetree.

Bronne oor die ekologie-krisis in die algemeen

Burger, A P et al 1983. Die mens en sy beperkte hulpbronne. Pretoria: SA Akademie.

Engelbrecht, B J 1988. Teologie en ekologie. HTS 44/1, 23-38.

Meadows, D L 1972. The limits to growth. New York: Universe Books. (Nederlandse Vertaling: Rapport van het Club van Rome 1972. Utrecht: Het Spectrum.)

Bronne oor bevolkingsgroei en beskawingsdruk

Burger, A P et al 1974. Die mens en sy beperkte hulphronne. Pretoria: SA Akademie.

Schoeman, B 1990. Bevolkingsgroei SA se grootste knelpunt. Die Transvaler 2 Maart 1990.

Venter, R 1990. Ontploffing van SA bevolking 'n probleem. Die Transvaler 8 Maart 1990. 
Wilsenach, A 1986. Afrika is nie ryp vir bevolkingsbeheer. Bulletin van die Afrika Instituut van $S A$ 25/8 \& 10.

Bronne oor lugbesoedeling en die 'kweekhuis-effek'

Brown, N 1988. Ramp staar aarde in gesig. Die Transvaler 1988.

Brundtland, G H 1989. Vyfpunt plan vir 'n beter aarde. Die Transvaler 29 Junie 1989.

Departement Nasionale Gesondheid 1991. Jaanerslag, Mei 1991. Pretoria: Staatsdrukker. [Ook in Die Transvaler 14 Mei 1991, bl 9.]

Die Rappon 1990. SA veg teen warm aarde in: Ons lewende wêreld. 11 Maart 1990. Myers, N 1991. Goue era of die hemele behoed ons. Endangered Wildlife Maart 1991. [Ook in Die Rapport 1991. Ons lewende wêreld. 3 Maart 1991, bl 7.]

Bronne oor waterbesoedeling in Suid-Afrika

Cochrane, K L 1983. Hartbeespoortdam: Are fish surviving? Stywe Lyne/Tight Lines Augustus 1983.

-.. 1985. The present and future condition of Hartbeespoortdam as angling ressort. Stywe Lyne/Tight Lines November 1985.

Pelser, K 1985. Bron van alle lewe. Publico 5/4, Desember 1985.

Bronne oor die afval-krisis

Anoniem, 1990. Kitseeu dompel die wêreld in 'n reuse afvalkrisis. Die Transvaler 8 Maart 1990.

Engelbrecht, B J 1988. Teologie en ekologie. HTS 44/1, 23-38.

Bronne oor die eensydige antropologiese wêreldbeeld

Buitendag, J 1985. Skepping en ekologie. Pretoria: Kitskopie.

Engelbrecht, B J 1988. Teologie en ekologie. HTS 44/1, 23-38.

Schoeman, M J 1990. Holisme: Die herowering van 'n ou wysheid in moderne konteks. HTS 46/3, 267-292.

Muir, J 1973. Sports Afield 169/6:95. 